\title{
LA REESTRUCTURACIÓN DE LOS ESPACIOS RURALES DE LA GOMERA: ¿DESARROLLO RURAL O PROFUNDIZACIÓN DE LA DIALÉCTICA CAMPO-CIUDAD?
}

\author{
Luis Manuel Jerez Darias \\ Universidad de La Laguna
}

\section{RESUMEN}

La isla de La Gomera es un territorio poco conocido desde el punto de vista científico, más aún, desde las ciencias sociales. Las mutaciones que ha sufrido a lo largo de la última centuria han tenido como telón de fondo la dialéctica entre el medio rural y el medio urbano, sobre todo, desde finales del mismo.

En la etapa de economía agraria, que absorbía a la totalidad de la Isla, esta dialéctica se caracterizó por el papel que jugaba Canarias, y La Gomera en particular, en el circuito agro-exportador internacional. Con la caída de ese modelo económico, que abrigaba en su seno la contraposición agricultura de exportación - agricultura de subsistencia, se abre un nuevo período caracterizado por la economía terciaria que, por medio de la actividad turística, ha ido reconvirtiendo el territorio insular en paralelo a una profundización de la dialéctica entre ambos espacios geográficos.

Palabras clave: La Gomera, Islas Canarias, agricultura, propiedad del suelo, emigración, turismo rural.

\section{ABSTRACT}

The island of La Gomera is a little known territory from a scientific viewpoint. It is even less known in the social sciences sector. The island has suffered from sudden changes throughout the twentieth centuary. The dialectics between the rural and urban enviroments have been the backdrop for these changes, above all at the end of the twentieth centuary.

In the phase of the agriculturally based ecconomy which extended over the whole of the island, the dialectics were characterized by the international export role played by the canaries and La Gomera in particular. With the downfall of this ecconomic model which protected the opposing position of agricultural exportation - subsistence agriculture, a new period opened, characterized by the terciary ecconomy. This, by means of tourism based activities has reconverted the insular territory on a paralel to a deeper dialectic between both geographical areas.

Key words: La Gomera, The Canary Islands, landownership, emigration, rural tourism. 


\section{El medio rural gomero: entre lo geográfico y lo socioeconómico}

La Gomera, con una superficie aproximada de $373 \mathrm{~km}^{2}$, es la segunda isla más pequeña del Archipiélago Canario. Se encuentra dividida en seis municipios: Agulo, Alajeró, Hermigua, San Sebastián, Valle Gran Rey y Vallehermoso; disponiendo las cabeceras municipales en los valles de sus barrancos más importantes, a excepción de Agulo (situado al pie de un impresionante acantilado) y Alajeró (en las medianías del municipio).

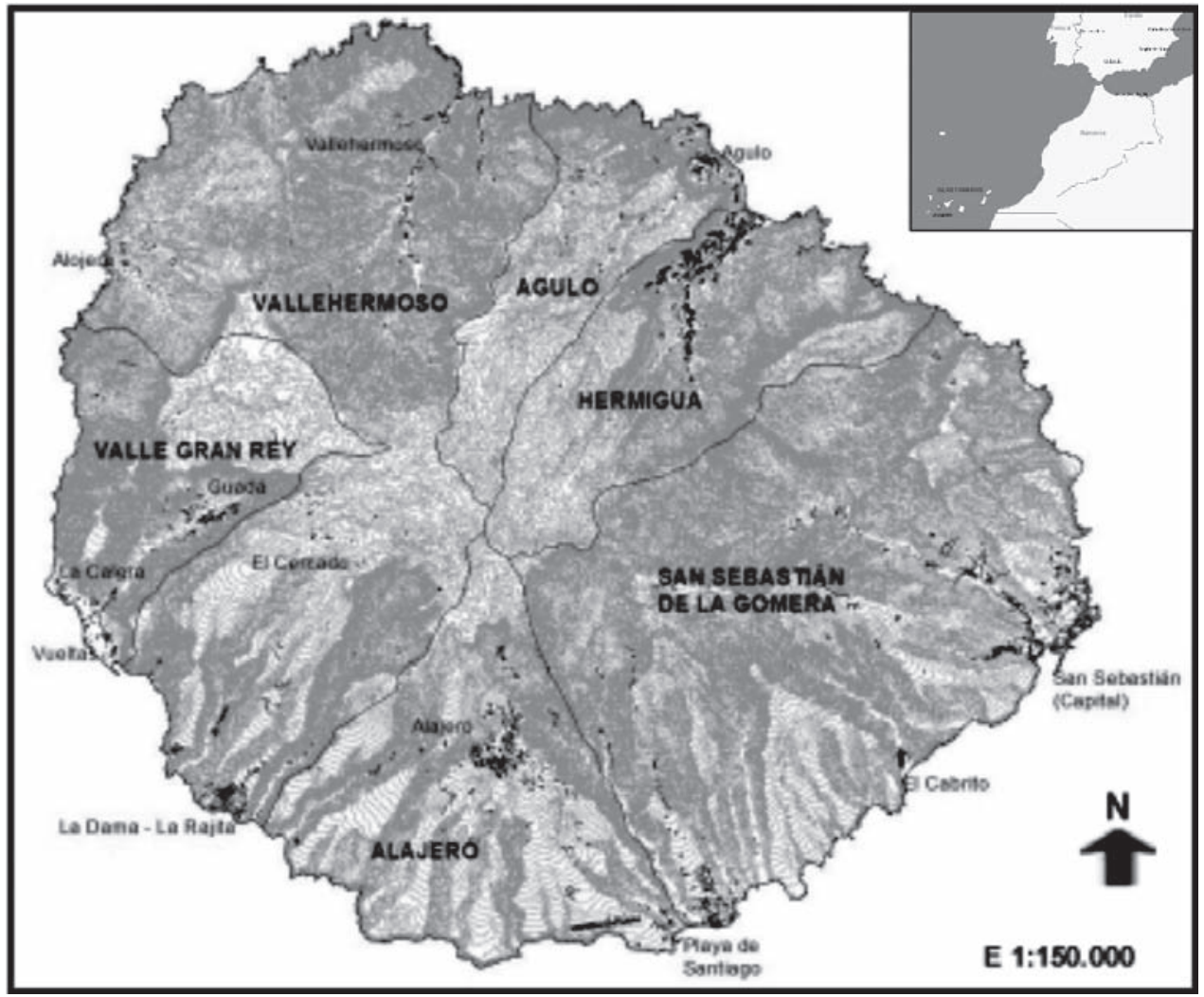

IMAGEN 1. Isla de La Gomera. Municipios y principales localidades.

Históricamente, la Isla ha jugado un papel marginal en el contexto del Archipiélago, estando subordinada a la vecina isla de Tenerife, la cual, ha actuado como reclamo y foco de absorción de la constante población emigrante de La Gomera. Esta población procedía, en su mayor parte, de las áreas rurales, ámbitos a los que queremos acercarnos en este artículo para explicar su evolución reciente.

Desde el proceso de conquista en el siglo XV hasta finales del XX el pilar fundamental de la economía isleña había sido la agricultura. Ésta se desarrollaba desde las tierras altas a la costa siguiendo dos modelos de explotación básicos: la agricultura de subsistencia (cereales, legumbres, tubérculos, hortalizas, etc.), generalizada a todos los ámbitos geográficos de la isla, y la de exportación (en orden cronológico: azúcar, orchilla, cochinilla, tomates y plátanos), por regla general, en cotas inferiores a los 300 metros. Por tanto, el 
medio rural gomero debemos asociarlo a la totalidad insular, por lo menos, hasta el último cuarto del siglo XX, período en el que algunas entidades de población fueron quedando al margen de la dinámica agraria.

Hasta fechas muy recientes, la población de La Gomera se distribuía por multitud de pequeños núcleos, a partir de los cuales se desplegaban las tierras de cultivo ${ }^{1}$. Estos enclaves se localizaban, principalmente, en la franja de medianías (400-800 m. de altitud), cerca de aquellos lugares con fácil acceso al agua, ya fuese por la existencia de afloramientos (Guadá, en Valle Gran Rey; Erque, Alojera y Epina en Vallehermoso; o La Laja y Vegaipala en San Sebastián, por citar algunos), o debido a al desarrollo de diferentes modos de captación (pozos, aljibes, embalses, canalizaciones, etc.).

Es a partir de la introducción de los tomates y los plátanos, junto a las factorías pesqueras del sur (ambos a principios del siglo XX), cuando comienza a configurarse la costa como un nuevo «espacio habitable» (Playa de Santiago en San Sebastián-Alajeró, La Dama en Vallehermoso, o los barrios de Vueltas y La Puntilla en Valle Gran Rey).

Tabla 1

DISTRIBUCIÓN DE LA POBLACIÓN EN 1950

\begin{tabular}{|l|c|c|c|c|}
\hline \multicolumn{1}{|c|}{ Municipio } & $\begin{array}{c}\text { Población } \\
\text { total }\end{array}$ & $\begin{array}{c}\text { Población de la } \\
\text { capital }\end{array}$ & $\begin{array}{c}\mathbf{N}^{\mathbf{0}} \text { de } \\
\text { diseminados }\end{array}$ & $\begin{array}{c}\text { Población en } \\
\text { diseminados }\end{array}$ \\
\hline Agulo & 2.486 & 1.048 & 3 & 1.438 \\
\hline Alajeró & 2.606 & 472 & 7 & 2.174 \\
\hline Hermigua & 5.376 & 871 & 30 & 4.505 \\
\hline San Sebastián & 6.664 & 2.869 & 19 & 3.795 \\
\hline Valle Gran Rey & 3.531 & 765 & 17 & 2.766 \\
\hline Vallehermoso & 7.720 & 1.024 & 30 & 6.696 \\
\hline \multicolumn{1}{|c|}{ TOTAL } & 28.383 & 7.049 & 106 & 21.374 \\
\hline
\end{tabular}

Fuente: Nomenclátor de 1950. I.N.E. Población de Hecho. Elaboración propia.

Los datos del cuadro 1 parecen confirmar que la población insular se hallaba disgregada en más de un centenar de asentamientos que acogían al 70\% de los habitantes; el 30\% restante se encontraba en las cabeceras municipales. Activos dedicados, fundamentalmente, a la agricultura, a excepción de una minoría ocupada en los otros sectores (Cuadro 2):

«Todos se dedicaban mayormente a la agricultura, de cereales, y a la ganadería, no abundaban los oficios...» (Sanz, 1999:13).

Únicamente la capital insular, por su condición de puerto y centro administrativo, «escapaba» a la supremacía de lo agrario. En ella se encuadraba, hacia la mitad de la centuria, la tercera parte de los trabajadores terciarios de la Isla (Burriel, 1982: 227).

1 Según Burriel (1982: 186), todavía «en 1970 los barrios de menos de 100 habitantes eran la mitad de los de la isla, y los de menos de 200 persona el 75\%; por encima de 500 habitantes sólo estaban los $<<$ cascos $>>$ o capitales municipales (excepto el de Alajeró), Playa Santiago y Laguna de Santiago-Tecina; y con más de 1.000 habitantes únicamente <<La Villa >> de San Sebastián, la capital insular». 
Tabla 2

ACTIVOS SEGÚN SECTORES ECONÓMICOS EN 1950

\begin{tabular}{|c|c|c|}
\hline ACTIVIDADES & $\mathbf{N}^{\mathbf{0}}$ & $\mathbf{\%}$ \\
\hline Agricultura & 7.315 & 81,2 \\
Pastoreo & 19 & 0,2 \\
Pesca & 314 & 3,5 \\
TOTAL PRIMARIO & 7.648 & 84,9 \\
\hline Construcción & 72 & 0,8 \\
Artesanos y obreros & 193 & 2,1 \\
TOTAL SECUNDARIO & 265 & 2,9 \\
\hline Comercio & 224 & 2,5 \\
Transportes & 119 & 1,3 \\
Servicios & 750 & 8,4 \\
TOTAL TERCIARIO & 1.093 & 12,2 \\
\hline TOTAL ACTIVOS & 9.006 & 100 \\
\hline
\end{tabular}

Fuente: BURRIEL, 1982: 24. Elaboración propia.

La actividad agrícola estaba determinada por relaciones de producción semifeudales, pues, las reminiscencias del Antiguo Régimen (Señorío), como la medianería, ocuparon un lugar destacado en la estructura agraria hasta fechas muy recientes; y se ejercía mediante técnicas muy rudimentarias.

«Aquí se estaba viviendo como en tiempos feudales. Había unos señores en Hermigua y Agulo, que estaban imponiendo su hegemonía política en la Isla» (García Luis y Torres, 1986:37).

«La tierra se la trabajaban los medianeros, los explotaban; el medianero estaba trabajando por menos de la mitad. Y claro, ellos vivían de eso. Existió el verdadero caciquismo. Hubo pobreza.»(García Luis y Torres, 1986:52).

«Si el $80 \%$ de la propiedad del cultivo del plátano está en medianería, significa que el productor directo del mismo no tiene propiedades en tierras, y si no optara por la medianería, en la agricultura, tendría que vender su fuerza de trabajo en otras actividades de diferentes ramas; en la localidad no existe la posibilidad de absorber tanta mano de obra. Por esto, o emigran o toman en régimen de medianería las tierras del cultivo del plátano... Por estas condiciones, que le obligan a quedarse aferrado a la tierra, la medianería es la relación de producción dominante.» (Reyes, 2002:169).

Relaciones derivadas de una estructura de la propiedad polarizada entre grandes y pequeños propietarios, y donde el troceamiento del terrazgo llega, en algunos casos, a niveles ridículos (multitud de parcelas inferiores a los $10 \mathrm{~m}^{2}$ ). Como dice el mismo autor para el caso de Hermigua, todavía, en 1975:

«... este bajo desarrollo de las fuerzas productivas está en función de la estructura agraria» (Reyes, 2002: 90). 
La estructura de la propiedad de la tierra en La Gomera se ha caracterizado por el predominio del minifundismo. Tras las desamortizaciones del siglo XIX las propiedades del señorío y de propios sufrieron una importante fragmentación que marcó las bases del parcelario que conocemos actualmente. Ese proceso de desintegración conoció varias líneas de desarrollo. Por un lado, el área de monte y algunas planicies de aprovechamiento secular ganadero quedaron bajo titularidad del Estado, por otro lado, el resto de la propiedad señorial pasó a manos de particulares, conformándose, a grosso modo, algunas áreas geográficas singulares:

a) Las de minifundio y microfundio en las medianías (400-800 m. de altitud), en las que se siguió practicando la agricultura de subsistencia (papas, legumbres, hortalizas, frutales), facilitada por la proximidad a las fuentes o nacientes de agua y orientada al abastecimiento familiar o local.

b) Las grandes parcelas ubicadas en las desembocaduras de los principales barrancos y en las lomadas. En las primeras se implantaron los nuevos cultivos de exportación (plátanos y tomates):

«Se trata de una agricultura localizada en la zona baja de la comarca [de Playa de Santiago], de tipo comercial...» (Plata, 1991: 115).

«En gran parte de las lomadas y barrancos de la zona media y baja se va a cultivar el tomate» (Plata, 1991: 117).

«Se dedicaron a él [al plátano] las mejores áreas de la zona baja de la comarca» (Plata, 1991: 118).

«...en el Valle Bajo [Hermigua], entre los 0 y los 150 metros está la zona de primera (del cultivo del plátano)» (Reyes, 2002: 47).

En las segundas se mantenía, de forma generalizada, el plantío tradicional de cereales, aunque en algunas lomadas sureñas se desplegaron los plátanos y los tomates gracias al aporte de agua canalizada desde las medianías.

El estudio del Catastro de Rústica de 1957 confirma nuestros planteamientos sobre la estructura de la propiedad ${ }^{2}$. Para ello nos hemos acercado a dos municipios con condiciones

Tabla 3

DISTRIBUCIÓN Y SUPERFICIE SEGÚN GRUPOS DE PROPIEDAD

\begin{tabular}{|l|c|c|c|c|}
\hline \multirow{2}{*}{$\begin{array}{l}\text { Tipo de } \\
\text { propiedad }\end{array}$} & \multicolumn{2}{|c|}{ AGULO } & \multicolumn{2}{c|}{ SAN SEBASTIÁN } \\
\cline { 2 - 5 } & $\begin{array}{c}\text { Propietarios } \\
\%\end{array}$ & $\begin{array}{c}\text { Superficie ocupada } \\
\%\end{array}$ & $\begin{array}{c}\text { Propietarios } \\
\%\end{array}$ & $\begin{array}{c}\text { Superficie ocupada } \\
\%\end{array}$ \\
\hline Pequeña & 92,2 & 12,2 & 77,7 & 14,0 \\
\hline Mediana & 7,2 & 35,1 & 17,3 & 24,5 \\
\hline Grande & 0,6 & 52,7 & 5,0 & 61,6 \\
\hline
\end{tabular}

Fuente: Catastro de la Riqueza Rústica de 1957. Elaboración propia.

2 Nuestra clasificación de la propiedad parte del concepto de dominio, del patrimonio superficial que aglutina un propietario (a escala, como mínimo, municipal) y no de la superficie según parcelas individualizadas. De este modo, la pequeña propiedad es aquella correspondiente a un patrimonio superficial inferior a las 5 hectáreas, la mediana es la comprendida entre las 5 y 19,9 Ha, y la grande con extensión igual o superior a las 20 Ha. 
geográficas y agro-parcelarias distintas: Agulo, situado al norte, el más pequeño de los seis $\left(25,39 \mathrm{~km}^{2}\right)$ y con fuerte minifundismo; el otro, San Sebastián, ocupa el sector SE de la Isla, cuadriplica al anterior en superficie $\left(113,59 \mathrm{~km}^{2}\right)$ y es el que posee las propiedades más extensas.

Como recoge el cuadro 3, en ambos municipios se manifiesta la enorme disparidad entre el número de propietarios de cada grupo con la cantidad de suelo que aglutinan, sobre todo, en la relación pequeña-gran propiedad, lo que deja al descubierto un profundo antagonismo de fuerzas que constituye la espina dorsal de la pobreza histórica del campesinado gomero, incluso mayor que las comúnmente citadas adversas condiciones geográficas (relieve abrupto, escasez de suelos, aridez, etc. $)^{3}$. Sólo una minoría, los grandes propietarios, poseía más de la mitad del suelo rústico catastrado en ambos municipios. Y sobre esta realidad (extrapolable al resto de municipios, en base, al actual estudio que estamos realizando de dicho catastro) se levanta el edificio de la semifeudalidad en el agro gomero, es decir:

«....un sistema de propiedad claramente polarizado entre la gran y pequeña propiedad, entre el latifundio y el minifundio, en el que los grandes propietarios de la tierra en lugar de introducir el capitalismo en el campo, atan al pequeño campesino y al campesinado sin tierra mediante relaciones sociales de producción que se fundamentan:

a) En el dominio de la tierra y el agua por unos pocos grandes propietarios.

b) En la extensión de la pequeña propiedad insuficiente y la expropiación campesina sin proletarización.

c) En el desarrollo de relaciones de producción semiserviles y en coacciones extraeconómicas.

El resultado es una agricultura atrasada, arcaica, poco productiva y que mantiene en un estado de miseria a la mayor parte del campesinado (Martín, 2006: 1-2).

Esta es la verdadera raíz de los problemas, atraso y, por ende, pobreza secular de La Gomera y, no tanto, por las restricciones que impone su medio geográfico.

Ante tales circunstancias la sociedad gomera tuvo que subsistir basculando entre la autarquía y la emigración.

\section{La evolución de la dialéctica campo-ciudad: crisis de la agricultura tradicional, emigración y polarización territorial}

Hasta mediados del siglo XX la contraposición campo-ciudad en La Gomera estaba definida por la función que desempeñaba ésta en el circuito agro-exportador internacional, es decir, como «finca» de implantación de ciertos productos demandados en el mercado europeo y peninsular. A partir de 1950 esta dialéctica se ramifica hacia espacios anteriormente «descartados», como el provincial. Este nuevo escenario se resuelve con el aporte

3 El discurso determinista ha sido el triunfante en la explicación del atraso económico insular. Es por ello que sean frecuentes alusiones como las siguientes:

«La economía de la isla está condicionada por una serie de factores naturales, insularidad, orografía, clima, etc., favorables unos, desfavorables otros, que determinan, en gran parte, su estructura económica.» (La Gomera 69: 22).

«Ello impidió [el quebrado relieve] la creación de mercados de carácter insular, fragmentándose el comercio en multitud de puntos de intercambio determinados por la topografía» (Gómez et al., 1988: 55)». 
de la mano de obra de los emigrantes gomeros (mayoritariamente campesinos) que se trasladaron, ya de forma definitiva, a las áreas urbanas de Tenerife o de la propia Gomera (a su capital), para trabajar como obreros de la construcción o en el sector servicios.

El contexto de España en esos momentos era muy difícil debido a las consecuencias de las contiendas bélicas (la dura década de 1940 con la crisis nacional derivada de la Guerra Civil y la II Guerra Mundial). Es el período de la autarquía, al que se ve sometido el régimen franquista por la «gran contienda mundial» y un bloqueo internacional que supuso la prohibición de la emigración y las transacciones comerciales con Europa (García Rodríguez, 1992: 96). Como bien dice Tébar: «El proceso de ruralización de la población durante los años cuarenta y primeros cincuenta fue manifiesto, produciéndose, incluso, el retorno a las zonas rurales de contingentes que habían emigrado en el primer tercio de siglo a las ciudades» (Tébar, 2006: 288).

A lo largo de dicha década la situación era insostenible en La Gomera al combinarse una alta población (la mayor de la historia con casi treinta mil habitantes ${ }^{4}$ ) y una débil estructura económica. La orientación autárquica supuso la potenciación de los cultivos de autoconsumo familiar con el objetivo de lograr un mayor grado de autoabastecimiento ${ }^{5}$. Y para poner en marcha esta política se roturaron tierras hasta entonces consideradas marginales desde el punto de vista agrario (García Rodríguez, 1992: 97). Estas tierras las constituían las laderas improductivas que, por su fuerte pendiente y fuerte erosión, eran prácticamente yermas para el desarrollo agrícola. Esta dificultad se ha solventado históricamente con el «abancalamiento» o creación de terrazas de cultivo «que presenta en La Gomera los niveles más elevados del Archipiélago». Sobre estos bancales, de difícil acceso y de escasa superficie, «que a veces es menor que la pared de contención, se ha asentado tradicionalmente la agricultura de subsistencia» (Rodríguez Brito, 1996: 80).

Efectivamente, el marco económico se ceñía a una actividad agrícola muy atrasada y que necesitaba de un enorme esfuerzo humano para mantenerse a flote. A pesar de que no existen muchos trabajos referidos a La Gomera, sí son comunes en casi todos ellos las referencias sobre la dureza de las condiciones de vida, del hambre y de la miseria de buena parte de su población, y que, unidas a otros factores, empujó a los isleños a buscar un mejor porvenir en otras tierras.

«Me marché por mis circunstancias de vida, porque aquí no había trabajo.... Yo por lo menos tenía una finca, de medias era, pero tenía una finca; la comida la tenía en realidad. Ahora, los demás se fueron ;huyendo del hambre! Aquí la vida ¡mal! Aún teniendo dinero, no había nada que comprar; y a veces mas que hubiera que comprar, no había dinero. Eran dos problemas igual. Así que......nos fuimos todos buscando otro porvenir.»(García Luis, 1995: 44).

A nuestro entender, esa situación de penuria fue consecuencia de la combinación de varios factores: por un lado, el fuerte grado de concentración parcelaria (elevada cantidad de pequeños propietarios contra un reducido grupo de grandes propietarios que aglutinaban más del $50 \%$ de la tierra), del que se deriva unas relaciones de producción semifeudales (medianería) y unas técnicas de trabajo vetustas; y por otro lado, la escasa diversificación

4 Los datos poblacionales que empleamos son los de la Población de Hecho, dado que la de Derecho incluye a los emigrantes que seguían empadronados en La Gomera.

5 Según Ricardo Guerra, en el periodo autárquico el Mando Económico promulgó una serie de normativas dirigidas a impulsar la agricultura de autoabastecimiento entre el campesinado de forma que los productos importados pudieran destinarse en mayor medida a cubrir la demanda urbana (Guerra, 2004: 419). 
Tabla 4

EVOLUCIÓN DE LA POBLACIÓN POR NÚCLEOS

\begin{tabular}{|c|c|c|c|c|c|c|c|c|}
\hline Municipio & Núcleos & 1930 & 1940 & 1950 & 1960 & 1970 & 1981 & 1991 \\
\hline \multirow{4}{*}{ Agulo } & Agulo & 1.129 & 1.202 & 1.048 & 1.024 & 786 & 741 & 590 \\
\hline & Lepe & 113 & 124 & 109 & 104 & 68 & 71 & 22 \\
\hline & La Palmita & 518 & 594 & 606 & 575 & 327 & 262 & 145 \\
\hline & Las Rosas & 593 & 653 & 723 & 746 & 463 & 337 & 257 \\
\hline \multirow{4}{*}{ Alajeró } & Alajeró & 399 & 428 & 472 & 387 & 314 & 244 & 229 \\
\hline & Arguayoda & 192 & 219 & 224 & 184 & 121 & 40 & 22 \\
\hline & Imada & 205 & 236 & 293 & 275 & 262 & 202 & 152 \\
\hline & Playa de Santiago & 616 & 793 & 872 & 780 & 563 & 442 & 577 \\
\hline \multirow{4}{*}{ Hermigua } & Las Cabezadas & 184 & 261 & 208 & 152 & 97 & 47 & 44 \\
\hline & El Cedro & 113 & 209 & 148 & 93 & 59 & 15 & 18 \\
\hline & El Estanquillo & 289 & 386 & 404 & 371 & 231 & 203 & 135 \\
\hline & Hermigua & 771 & 1.157 & 871 & 820 & 674 & 646 & 450 \\
\hline \multirow{4}{*}{$\begin{array}{c}\text { San } \\
\text { Sebastián }\end{array}$} & Benchijigua & 152 & 151 & 188 & 118 & 28 & 13 & 5 \\
\hline & Jerduñe & 184 & 242 & 304 & 227 & 84 & 36 & 13 \\
\hline & Laguna de Santiago & 602 & 946 & 937 & 1.013 & 684 & 542 & 977 \\
\hline & San Sebastián & 2.694 & 2.856 & 2.869 & 3.820 & 3.182 & 4.129 & 4.717 \\
\hline \multirow{4}{*}{$\begin{array}{l}\text { Valle Gran } \\
\quad \text { Rey }\end{array}$} & Arure & 366 & 407 & 388 & 344 & 259 & 309 & 139 \\
\hline & La Calera & 725 & 743 & 765 & 512 & 475 & 490 & 440 \\
\hline & Las Hayas & 134 & 146 & 144 & 130 & 123 & 86 & 70 \\
\hline & Taguluche & 205 & 247 & 212 & 222 & 133 & 104 & 76 \\
\hline \multirow{4}{*}{ Vallehermoso } & Arguamul & 142 & 169 & 257 & 219 & 85 & 50 & 47 \\
\hline & Erque & 85 & 101 & 121 & 104 & 48 & 37 & 11 \\
\hline & La Dama & 203 & 312 & 523 & 482 & 330 & 373 & 225 \\
\hline & Valle de abajo & 557 & 672 & 675 & 565 & 377 & 308 & 210 \\
\hline
\end{tabular}

Fuente: Nomenclátor de Población. I.N.E. Población de Hecho. Elaboración propia. En negrita se señalan las máximas poblacionales.

económica existente, pues fuera del marco agrario sólo existía una limitada actividad pesquera en los núcleos sureños y un sector terciario ínfimamente representado en las capitales municipales (sobre todo en San Sebastián). Y si esto se conjuga con una fuerte presión demográfica ${ }^{6}$, el éxodo rural estaba servido.

6 Según Burriel, en 1940 existían 80 habitantes por $\mathrm{Km}^{2}$ y, tan sólo, el 10\% del territorio insular era apto para la agricultura, con 1.000 hectáreas de regadío y tres pequeñas fábricas de conservas de pescado (Burriel, 1982: 194). 
«La agricultura tradicional de autoconsumo, carente de proyección económica, ha convertido al campo gomero en fuente de aprovisionamiento de mano de obra para otros sectores de la producción más y mejor remunerados (construcción y servicios), siendo a la vez esta emigración causa final del hundimiento de la agricultura.» (Rodríguez Brito, 1996: 96).

Así pues, los años cincuenta se abren con un proceso emigratorio que, en tan sólo dos décadas, «despuebla» la Isla ${ }^{7}$. Esta sangría afectó considerablemente a las zonas de agricultura tradicional, a los núcleos de las medianías que tuvieron su esplendor demográfico a lo largo de las décadas centrales del siglo (Cuadro 4). En cambio, y paralelamente a la emigración exterior, también tenían lugar los trasvases poblacionales interiores desde esos núcleos en proceso de abandono hacia los enclaves costeros meridionales (asociados a la agricultura de exportación y factorías pesqueras en Playa de Santiago, Valle Gran Rey o La Rajita-La Dama), y a la capital insular.

Comienza, de esta forma, la polarización territorial en La Gomera como expresión del cambio que sucede en la base económica española con el reemplazo de las actividades primarias por las secundarias y terciarias. Esta sustitución de centro geoeconómico de las medianías por la costa tuvo lugar a partir de la década de los sesenta y será un fenómeno que no hará más que agudizarse con el tiempo.

De los diferentes espacios de acogida, fueron San Sebastián, Playa de Santiago y Valle Gran Rey los que se consolidan como referentes socioeconómicos, sobre todo el primero.

San Sebastián siempre tuvo importancia por su función administrativa y portuaria. Pero el hecho capitalino no fue históricamente un factor decisivo para su crecimiento demográfico. Sólo a partir de los cambios sufridos en la estructura económica (con el predominio de las actividades terciarias) fue cuando se encumbró como centro indiscutible de la Isla. Los datos de la Tabla 4 reflejan un crecimiento demográfico continuo pues, a pesar de verse también afectada por la emigración, fue el municipio que más emigrantes del campo acogió (Jerez, 2004: 7-8); un claro ejemplo e inicio de la dialéctica campo-ciudad en La Gomera con el traslado de la mano de obra del campo tradicional a participar en las actividades terciarias y de la construcción en la capital.

La comarca de Playa de Santiago (repartida entre los municipios de Alajeró y San Sebastián) comenzó a tener la hegemonía poblacional entre los núcleos sureños a partir de la década de 1930, debido a la llegada de dos empresas foráneas: la noruega Fred Olsen ${ }^{8}$ y la tinerfeña Rodríguez López. Ambas empresas se dedicaban al sector agroexportador y la segunda, también, a la industria pesquera (fábrica de conservas). Pero la magnitud de estas compañías trascendía a la escala comarcal, pues, según los datos de Catastro de Rústica de 1957, no sólo eran los mayores propietarios de la zona, sino de la Isla, con un patrimonio de 7 y $13 \mathrm{Km}^{2}$ respectivamente, además de poseer embarcaciones para trasladar los productos al exterior ${ }^{9}$, y de construir diferentes proyectos hídricos para poner en marcha sus explotaciones agrícolas:

7 Según los datos del censo, la población de La Gomera pasó de 28.383 habitantes en 1950 a los 15.858 en 1991. Este contingente poblacional se trasladó mayoritariamente a Tenerife y Venezuela.

8 Esta empresa tuvo como nombres precedentes en La Gomera sociedad «The Norwegian Canary Agriculture (Tecina) Limited», «Bienes Tecina Comunidad» o «Agrupación Noruega» entre otras. Fred Olsen S.A. es el nombre actual y con el que se ha conocido comúnmente.

9 En un principio la empresa canaria era la encargada del transporte de los productos desde La Gomera a Tenerife. Ya a mediados de los 70 será la empresa noruega (mediante el Ferry Gomera) la encargada del transporte de todo tipo de mercancías y pasajeros desde San Sebastián a Los Cristianos en Tenerife. 
«Las dos $<<$ grandes $>>$ empresas,....acometen, en un primer momento, dos proyectos hídricos:

- Canalización de las dos corrientes naturales de agua....que se encontraban en la parte alta de la comarca.

- Construcción de una serie de <<presas >> que pudieran retener el agua de las escasas precipitaciones.

Con estas dos realizaciones, ya la zona baja de la comarca, podía comenzar su transformación en zona alta para el cultivo» (plata, 1991: 94) ${ }^{10}$.

En la década de los setenta la empresa canaria concluye sus actividades en la comarca y la noruega comienza con una política de reestructuración económica dejando «al margen» la actividad agrícola para orientarse, definitivamente, hacia el sector servicios (transporte marítimo y actividad turística).

Valle Gran Rey fue otro de los municipios favorecidos por el nuevo contexto económico ${ }^{11}$. La crisis que afectó a sus medianías fue «sostenida» por el fuerte desarrollo de la platanera en la plataforma costera y por la incipiente actividad turística surgida a partir de los sesenta. Así pues, con el paso de los años, ha pasado del binomio agricultura-pesca al desarrollo turístico, consolidándose actualmente como el principal centro turístico y el segundo municipio más poblado (después de San Sebastián). A diferencia de Playa de Santiago, Valle Gran Rey ha experimentado esta evolución con fuerte presencia de la iniciativa local. Mientras el primero — como tuvimos ocasión de ver- fue un enclave de «juego» de los intereses foráneos, en Valle Gran Rey, a pesar del potencial de la iniciativa extranjera, no ha sido menos la local.

En cambio, los municipios del Norte (Agulo, Hermigua y Vallehermoso) no terminan de levantarse de los azotes de la crisis. La terciarización de la economía gomera, enfocada hacia lo turístico, no ha supuesto el desarrollo de estos espacios. Ante este panorama, las propuestas de dinamización para estos municipios «rurales» tratan de buscar los intersticios posibles para insertarlas en el sistema, siendo notables las ingentes inversiones públicas (infraestructuras, subvenciones, planes de desarrollo, etc.) como fórmula que estimule la escasa y débil iniciativa privada. En definitiva, la coyuntura actual tiende, más que nunca, a la especialización de los espacios marginales de la Isla, tratando de encaminarlos hacia lo terciario, ya sea de forma directa (turismo rural) o indirecta (como lugares «idílicos» donde los turistas que se alojan en otros lugares puedan disfrutar de espacios de ocio).

\section{De lo agrario a lo terciario: ¿homogenización geográfica o profundización de la dialéctica campo-ciudad?}

En términos globales, desde mediados de los años 1990, el medio rural gomero está siendo testigo de la nueva funcionalidad que se le ha asignado como medida de revitalización socioeconómica. Esta reorientación trata de adjudicarle un cometido inédito; ya no vale su carácter productivo, sino de uso, imprimiéndoles una complejidad que, aunque parezca difuminar la dicotomía medio rural / medio urbano — por la similitud funcional一, no hace sino ampliar la brecha entre ambos, al ligar el primero a los intereses y demanda del segundo.

10 Las dos «grandes empresas» a las que alude el autor fueron: la compañía mercantil Fred Olsen S.A. y Álvaro Rodríguez López, S.A. Entre ambas se repartían casi la totalidad de la zona baja de la comarca de Playa de Santiago.

11 Según el Nomenclátor de población, hasta 1930 el municipio era conocido por Arure; a partir de dicha década pasó a denominarse Valle Gran Rey. 
Si anteriormente el medio rural se definía —económicamente hablando- sobre la base de la actividad agrícola como función rectora, en este nuevo ciclo estamos asistiendo a una terciarización del mismo, en el que algunas actividades del sector servicios, principalmente el turismo rural, son las que están definiendo estos espacios. Como dice Segrelles: el campo pasa en un breve lapso de ser un factor de producción a convertirse en un bien de consumo (Segrelles, 2001: 44).

Entonces, si el medio rural gomero se está terciarizando, ¿dónde aparece la dialéctica campo-ciudad cuando dicho proceso de terciarización debiera uniformar tales espacios? Pues, a nuestro parecer, en varias vertientes:

a) En el tipo de agentes que dirigen su reestructuración, su nueva «plurifuncionalidad», principalmente agentes urbanos que, en muchos casos, tienen influencia directa en las decisiones políticas que los afectan (ordenación territorial, planeamiento urbanístico, subvenciones, etc.).

b) En la subordinación que mantiene frente a la demanda urbana, como áreas de ocio para los habitantes de la ciudad y como reserva para el abastecimiento del mercado local.

Esta metamorfosis del espacio rural gomero no es un proceso ajeno al ocurrido en el contexto internacional, principalmente al europeo. Los acontecimientos que se están materializando desde hace algunos años en La Gomera derivan de una situación geopolítica concreta, precisamente por su integración en la UE, la cual ha tenido que reajustar diversas políticas (entre ellas la agraria: PAC) para mantenerse en primera línea de la competencia económica mundial ${ }^{12}$.

El proceso de cambio sucedido en las sociedades post-industriales desde finales de la década de 1980, en lo referente a los valores medioambientales y el mundo rural europeo, ha supuesto una reorientación funcional del mismo (Molinero, 2003: 23). Estos cambios, derivados del proceso de mundialización económica (liberalización, fuerte competencia y elevados precios), empujaron a la UE a diseñar nuevas fórmulas para impulsar sus espacios agrarios. El modelo trazado se dirigió hacia una regeneración que imbricase las actividades primarias, las terciarias y la protección medioambiental y cultural. Se busca la revitalización rural, pues a las zonas rurales se las considera «una prioridad para la UE» según la Declaración de Cork en 1996 (González, 2001:37). Dentro de estas zonas desfavorecidas se encuentran las llamadas «regiones Objetivo 1», las consideradas como las más atrasadas por la política regional europea, entre las que se encuentra Canarias.

Para poner en marcha esta nueva estrategia se han creado una serie de iniciativas comunitarias (LEADER y PRODER) y la reorientación de algunos fondos estructurales (FEDER, FEOGA y FSE) que intentan fomentar el desarrollo rural, los equilibrios regionales, la mejora de las zonas desfavorecidas, etc. En Canarias se han aplicado las iniciativas LEADER (I y II), y concretamente en La Gomera el LEADER II (aprobado en 1994).

La mayor parte del gasto del LEADER II en La Gomera se centró fundamentalmente en el desarrollo del turismo rural (al igual que en el resto del Archipiélago), y en la con-

12 Según Segrelles, estas nuevas políticas no se hubieran llevado adelante de «no ser por las presiones internacionales derivadas de la progresiva liberalización comercial en el mundo (EEUU y el Grupo de Cairos, GATT, OCM) y por meras cuestiones económicas en el seno de la propia UE. Es decir, de la necesidad se ha hecho virtud. La producción crónica de excedentes y los enormes gastos presupuestarios del FEOGA-Garantía constituyen los principales factores que despiertan la conciencia ecológica y ruralista de Bruselas» (Segrelles, 2001: 47). 
servación y mejora del medio ambiente (Febles, 2003: 284). Esta aportación ha facilitado la rehabilitación de numerosas viviendas tradicionales que han sido destinadas por sus propietarios, principalmente urbanos, a alojamientos rurales.

El turismo rural tiene sus inicios en la Isla a mediados de la década de los setenta pero de forma exigua y sin distinguirse como tal. Es a partir de los años ochenta cuando, de la mano de europeos, se comienzan a rehabilitar viviendas rurales (que previamente eran compradas a sus propietarios, muchos de ellos personas que habían emigrado de la Isla) para ocuparlas directamente como residencia de vacaciones o bien para destinarlas al alquiler. Arranca de esta forma un nuevo modelo de turismo no asociado al litoral y que en los noventa cristalizará como producto diferenciado debido, en parte, a un aumento de la demanda y, sobre todo, a la inversión pública (LEADER II, Gobierno de Canarias, Cabildo). De no ser por las subvenciones públicas esta actividad no habría conocido el auge que ha tomado desde entonces, sobre todo en los municipios de economía estancada, es decir, en los del norte (Agulo, Hermigua y Vallehermoso) (Figura 1).

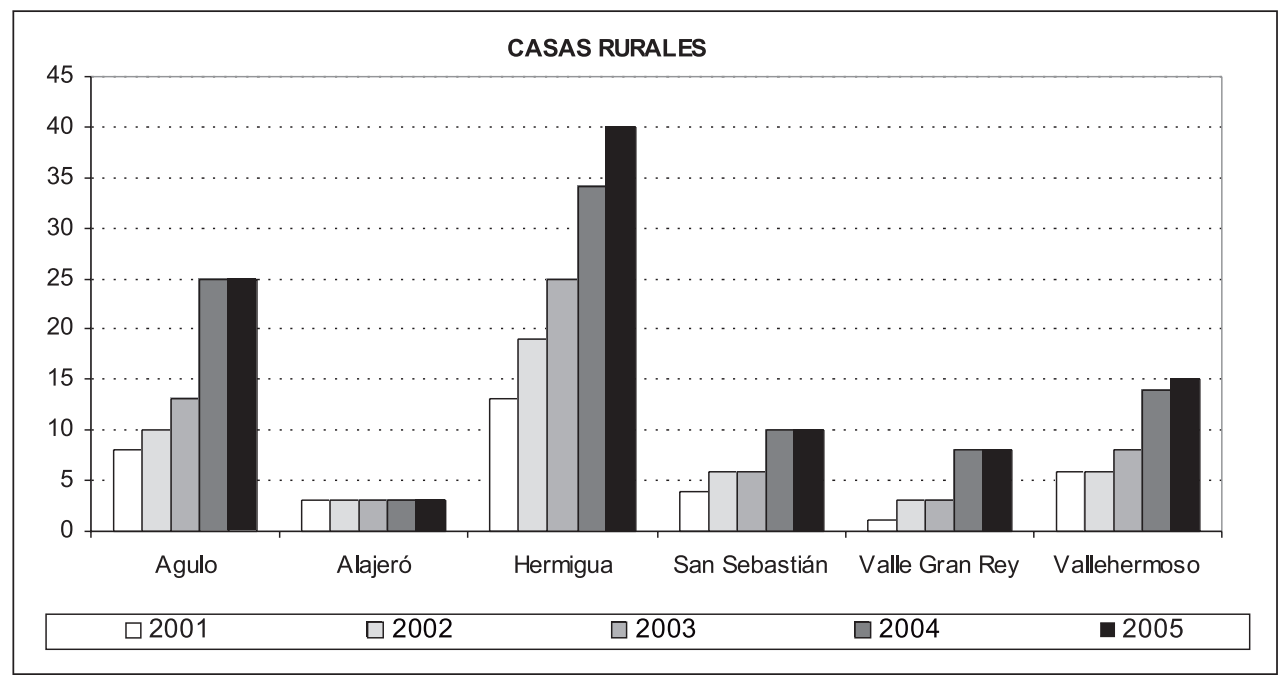

Figura 1. Desarrollo de casas rurales en La Gomera (2001-2005).

Fuente: Consejería de Turismo. Gobierno de Canarias. Elaboración propia. ${ }^{13}$

La irrupción del turismo rural como nueva fórmula de revitalización de los espacios agrarios está dando lugar a una singular configuración geográfica de los mismos. Por un lado, se encuentra el hinterland insular, donde se entremezclan los asentamientos rurales (con los usos residencial, turístico y agrario) y aquellos espacios a constituirse como lienzos y territorios museísticos adecuados para el esparcimiento y conocimiento de la naturaleza

13 El gráfico sólo nos aporta una imagen sesgada del fenómeno urbanizador destinado al turismo rural en la Isla, pues en el mismo sólo se incluyen las casas rurales autorizadas, dejando al margen las viviendas turísticas de uso rural y los hoteles rurales (3). Según el «Estudio Guía para la adecuada implantación del turismo rural en el entorno del Parque Nacional de Garajonay» (en adelante Estudio-guía), en el año 2004 la relación entre establecimientos legales e ilegales suponía un sesenta y un cuarenta por ciento respectivamente de la oferta de turismo rural en la Isla. 
y la cultura (ENP); y por otro lado, las villas o cabeceras municipales que se consolidan como centros de servicios y como «espacio laboral» para los habitantes de los núcleos que existen a su alrededor. Ahora bien, tanto en unos como en otros se asiste a la dialéctica imperante en la actualidad entre los usos urbanos y el medio natural (tierras de cultivos y espacios protegidos), situación estimulada, en gran medida, por el turismo rural, pues éste se caracteriza por su carácter disperso y excesiva difusión de las iniciativas. Una dispersión que es importante, sobre todo, en los municipios norteños, donde la evolución de casas rurales va en continuo aumento.

Es más, esta dialéctica no es sino la expresión del débil desarrollo socioeconómico insular, el cual necesita de una fuerte inversión pública para poner en marcha a estos espacios marginales, tanto desde las instancias europeas como de la nacional, regional, insular y local. Cada una de ellas opera de diversa forma. La Administración europea establece los programas y la inversión asociada a los mismos; el Gobierno central cumple una función de promoción y comercialización además de inversora (por ejemplo a través del Ministerio de Medioambiente); el Gobierno regional asume un cometido legislativo (Ley de Ordenación del Turismo de Canarias, Directrices de Ordenación del Turismo de Canarias, etc.), de fomento, difusión, comercialización y sanción ${ }^{14}$; el Cabildo Insular realiza la planificación, ordenación y facilita la actividad turística (PTEDT, PIOG, autorizaciones), de promoción e inspección; y los ayuntamientos también ejercen una función de promoción, planificadora (planes generales, parciales, etc.) y concede las licencias de obras.

Así es, grosso modo, como queda organizada la pirámide burocrática vinculada a la actividad turística y a la reorientación del espacio rural de la Isla, teniendo en su base, como agentes esenciales, a la Administración Local y, sobre todo, a la Insular.

El Cabildo es el activo más influyente en el actual modelo de desarrollo del medio rural al ser la entidad que posee las competencias fundamentales con respecto a las nuevas exigencias planteadas. Desde su función panificadora - bien sea por medio del Plan Insular de Ordenación como por el Plan Territorial Especial de Desarrollo Turístico—-, determina en qué lugares y cómo se van a desarrollar las diferentes actividades, principalmente, la turística. No debemos olvidar que fuera de los ámbitos urbanos (núcleos urbanos propiamente dichos y los asentamientos rurales y agrícolas en el medio rural) donde los ayuntamientos rigen la actividad urbanizadora, es el Cabildo - por medio de las calificaciones territoriales-el que facilita la construcción, rehabilitación, ampliación o legalización de edificaciones en suelo rústico, además, y no menos importante, también se encarga de ejecutar infraestructuras fundamentales como antesala de la ulterior urbanización (carreteras, instalaciones hidráulicas, etc.). El fenómeno de urbanización del campo viene precedido, casi siempre, por la ejecución de infraestructuras. Éstas «suponen el primer elemento de articulación del espacio rural en el conjunto del territorio y una condición esencial de la integración económica»; en particular, las infraestructuras de transporte, ya que permiten el acceso de la población y de los turistas a los centros de servicios (Nogués, 19).

La nueva lógica <<apuesta por un rural postproductivista que dentro de un sistema territorial focalizado en las ciudades se convierte en una especie de "gran parque urbano» >> (Rodríguez González, 2001:62). Efectivamente, una buena parte del espacio rural gomero pretende configurarse como un lugar opuesto a los enclaves turísticos

14 Al respecto, cabe mencionar el papel jugado por el Plan de Medianías como programa inversor para el desarrollo rural. De ser un plan de actividad directa ha pasado en los últimos años a constituirse como un mero mecanismo de intermediación presupuestaria entre el Gobierno regional y la administración insular y local. El Gobierno de Canarias canaliza a través de este Plan cuantiosos fondos (más de 6 millones de euros anuales) para ser destinados a la ejecución y mejora de infraestructuras y proyectos diversos en el medio rural de la Isla. 
meridionales, al modo tradicional de sol y playa. De ahí, el buen número de Espacios Naturales Protegidos declarados (17), que suponen el 33\% de la superficie insular, a la que se podría sumar la superficie de otras categorías de protección como los Lugares de Importancia Comunitaria, que en total daría un valor aproximado de un 50\% de superficie protegida para la Isla.

Hasta la propia actividad definitoria de estos espacios, la agricultura, tiende a dejar atrás su función productivista para convertirse en una tarea de conservación, protección y gestión del medio ambiente. Habiendo desaparecido, casi por completo, la agricultura de exportación vinculada a grandes explotaciones, la de tipo familiar pasa a convertirse en una especie de recurso invisible, inmaterial y no orientada al comercio. La nueva forma de percibir la agricultura y de justificar su apoyo está asociada a una actitud proteccionista que la desliga de los mercados, de la producción y de las propias explotaciones agrarias en su conjunto, para enfocarla «al mantenimiento de superficies aunque no produzcan, a las buenas prácticas agrarias no dañinas para el ambiente, a la reforestación, o la preservación del paisaje» (De la Puente, 2002: 235). Eco que ha tomado la Administración:

«Sin embargo es necesario, entender y valorar la importancia de estas pequeñas explotaciones en la actualidad, debido a que se han puesto en cultivo suelos que se estaban perdiendo y explotaciones que se habian abandonado hace 40 años, y que están contribuyendo en la actualidad a mantener e incluso recuperar parte de un paisaje rural y agrario que es sin duda constitutivo de una gran parte de la riqueza cultural y paisajística intrínseca de La Gomera, y que sin duda atraen una parte importante del turismo actual y cuyo desarrollo y crecimiento depende del mantenimiento de estos paisajes» (Plan Territorial Especial del Desarrollo Turístico de La Gomera, pp. 207).

Por eso hoy el nuevo discurso empieza a sostener un argumento «proteccionista» y se asiste a un proceso en el que las administraciones públicas están interesadas en promover e implantar las diversas modalidades de turismo rural y de naturaleza (Vera, 1997: 133). Apuesta que no deja de ser ambigua pues, por un lado, se redunda en la idea del desarrollo sostenible y, por otro, plantea modelos de crecimiento incongruentes con dicho ideario, y no sólo desde el punto de vista medioambiental, sino, también, socioeconómico ${ }^{15}$.

De la lectura del Plan Especial de Desarrollo Turístico se desprende una apuesta inequívoca por el turismo convencional y de masas. Según sus proyecciones de crecimiento, para el horizonte 2015 se prevén unas 17.723 plazas, de las que 15.200 son de Turismo Convencional $^{16}$ (hotelera y extrahotelera) y 2.523 de Turismo Rural con 1.214 y 1.182 plazas para las categorías de «turismo rural» $\mathrm{y}$ «turismo asimilable» respectivamente ${ }^{17}$. Y es la

15 En dicho Plan se propone para el año 2015 una población total de 47.304 habitantes, como sumatorio de 17.723 plaza alojativas y 29.581 habitantes de población residente (PTEDT, pp. 193). La máxima histórica de La Gomera se situó en torno a los 30.000 habitantes (población de hecho) en la década de 1940, produciendo la mayor presión antrópica sobre el territorio hasta entonces. La sangría emigratoria fue la posterior solución, aunque las causas no fueron de índole determinista sino socioeconómicas (semifeudalidad en el campo, fuerte concentración de la propiedad, represión política, falta de alternativas económicas, etc.).

16 El Plan apuesta claramente por la modalidad hotelera con categoría de 5 ó 4 estrellas con actividad turística complementaria (campo de golf, puerto deportivo, etc.).

17 El turismo rural es el que se desarrolla en edificaciones tradicionales preexistentes susceptibles de ser intervenidas para su adecuación al uso turístico mediante rehabilitación y/o ampliación. Por su parte, el turismo asimilable se practica en edificaciones con características similares a las anteriores pero con el hecho diferencial de que podrían ser de nueva planta. 
segunda categoría, la de «turismo asimilable», la más destacada; en primer lugar, porque permite la edificación de nueva planta y, en segundo lugar, por su inclinación a favor de la figura del «hotel rural».

El hotel rural, a diferencia de la casa rural — vinculada a la economía familiar-, necesita de una considerable inversión (infraestructura, personal, promoción, servicios, etc.), por lo que es común que sean empresas que cuentan con un importante nivel de financiación las que los promueva. Estas empresas, generalmente, las constituyen agentes ajenos al mundo rural, con presupuestos culturales urbanos y mercantiles alejados de la lógica que ha sostenido secularmente estos espacios (Ortega, en VVAA, 2004: 90, 109). Además, sus canales de comercialización suelen ser agencias de viajes o touroperadores nacionales e internacionales, dejando a un lado el asociacionismo local como fórmula de coordinación, promoción y gestión ambiental de la oferta turística.

En el año 2004 el número aproximado de empresas de intermediación y «gestión integral» (realizan labores de promoción, comercialización, mantenimiento, limpieza, etc.) que operaban en la Isla era de 203, de las que sólo 12 poseían su sede o sucursal en La Gomera. Y no sólo esto, sino que la mayor parte de las empresas que desarrollan actividades complementarias al turismo (senderismo, excursiones, buceo, rent a car, etc.), son también foráneas. A modo de ejemplo, podemos citar que de las 69 empresas de senderismo que intervenían en 2004 en la Isla, 63 eran foráneas y sólo 6 tenían su sede en misma ${ }^{18}$ (Estudio-guía, pp. 58-61, 186).

Estos datos parecen mostrar que, cada día más, estas opciones son ofrecidas por los propios operadores turísticos que comercializan las modalidades tradicionales masivas de sol y playa (Martínez, 2001: 336). De querer plantear un modelo de turismo que se constituyera como palanca de impulso para la población local de nuestros espacios en crisis se está pasando a un negocio controlado, cada vez más, por agentes foráneos y destacados del emporio turístico masivo.

\section{Conclusiones}

El objeto de este artículo era responder a la pregunta que planteamos en el título del mismo: ¿Desarrollo rural o profundización de la dialéctica campo-ciudad?

El análisis evolutivo que hemos hecho del medio rural gomero parece confirmar que la dialéctica entre los espacios urbanos y los rurales no tiene atisbos de desaparecer sino, más aún, de incrementarse. De tener una funcionalidad concreta durante siglos, desde finales del XX ha pasado a configurarse como un espacio ecléctico en el que se tratan de combinar diferentes funcionalidades como respuesta a la dura crisis que los azotó desde mediados de la centuria.

A partir de 1950 el campo gomero fue escenario de un profundo proceso de despoblamiento a favor de las áreas urbanas y sur de Tenerife, Venezuela y núcleos meridionales de La Gomera, sobre todo de su capital.

Los antiguos campesinos pasaron a formar parte de los dos nuevos sectores en alza y que no tardarían en constituirse como los referentes de la economía canaria, a saber: el terciario, teniendo como máximo exponente la actividad turística, y el sector de la construcción.

$18 \mathrm{Al}$ respecto debemos decir que la localización de la sede en la Isla no implica directamente que la empresa sea de personas de La Gomera. Algunas de estas empresas de ocio son creadas por foráneos que residen o vienen con frecuencia a la Isla y registran fiscalmente su negocio en la misma. 
Sobrevino de esta forma una polarización territorial con un hinterland y un sector septentrional en pleno hundimiento y unos enclaves meridionales costeros que actuaron como los centros de inversión y desarrollo insular.

Han quedado, por tanto, dos espacios geográficos bien diferenciados: las tres entidades de población sureñas (San Sebastián, Playa de Santiago y Valle Gran Rey) por un lado y, por otro, el resto del territorio insular. El primero ha marcado como ruta de desarrollo la actividad inmobiliaria-turística y el segundo se está fraguando como un espacio terciarizado, tomado como punta de lanza la omnipresente actividad turística. Una actividad dirigida por agentes externos a las comunidades rurales de La Gomera, ya sean privados o públicos.

Este cambio de funcionalidad no está yendo paralelo a una ruptura de la subordinación del medio rural con respecto al urbano. El espacio rural de la Isla sigue sometido a los intereses y demanda urbana, al que se le imponen nuevas formas de vida y relaciones con el territorio. La agricultura ha ido perdiendo, cada vez más, su papel productivo a favor del mantenimiento del paisaje, de un paisaje para ser consumido por los urbanos como escenario que sintetiza el medio ambiente y la cultura.

Por tanto, la situación actual no es sino la expresión evolutiva de la histórica contraposición entre el medio rural y el urbano. Si anteriormente ésta se explicaba por la función de finca y suministradora de alimentos para la ciudad, ahora lo es como lugar de ocio y esparcimiento. El nuevo contexto, impulsado desde el entorno internacional (UE) y plasmado en la práctica por el poder local (Gobierno Autónomo, Cabildo y Ayuntamientos) no termina de concretar el argumento del desarrollo rural con implicación de la población local. Al final, este discurso parece haber quedado en un mero argumento pues las leyes del mercado, la legislación, la planificación, etc., están abriendo «legítimamente» las puertas a la inversión de las clases urbanas, quienes con más capacidad económica, práctica y de gestión van en camino de monopolizar la nueva funcionalidad de los espacios rurales.

\section{Bibliografía}

BURRIEL, E. L. (1982): Canarias: Población y Agricultura en una Sociedad dependiente. Oikostau. Barcelona, $242 \mathrm{pp}$.

DE LA PUENTE, L., (2002): «El paisaje agrario en el discurso territorial de la PAC y en la ordenación de los espacios rurales», en Los espacios rurales entre el hoy y el mañana. XI Coloquio de Geografía Rural. Universidad de Cantabria. Santander, pp. 233-242.

ECOTURAL GOMERA. Estudio Guía para la adecuada implantación del turismo rural en el entorno del Parque Nacional de Garajonay. [En línea]. La Gomera: Ecotural Gomera, 2005. <http://www. ecoturismocanarias.com/gomera/estudio/index.htm>. [15 de mayo de 2007].

FEBLES, M. F. (2003): «Desarrollo rural en Canarias: el programa LEADER II», en García Rodríguez, J.L. Desarrollo rural en territorios insulares: especial referencia a las Islas Canarias. Excmo. Cabildo Insular de La Palma, Centro de Cooperación y Desarrollo Territorial de la Universidad de Oviedo. Santa Cruz de La Palma, pp. 271-290.

GARCÍA LUIS, R. y TORRES, J.M. (1986): Vallehermoso: «El Fogueo». Tagoror de ediciones. La Laguna, $304 \mathrm{pp}$.

GARCIAA LUIS, R. (1995): Estrella Polar: un viaje clandestino Canarias-Venezuela, 1948. Bailes el Sol. Tegueste, $181 \mathrm{pp}$.

GARCÍA RODRÍGUEZ, J. L. (1992): Emigración y agricultura en La Palma. Consejería de Agricultura y Pesca del Gobierno de Canarias-Excmo. Cabildo Insular de La Palma. Santa Cruz de Tenerife, 387 pp.

GARCÍA RODRÍGUEZ, J. L. (2003): Desarrollo rural en territorios insulares: especial referencia a las Islas Canarias. Excmo. Cabildo Insular de La Palma, Centro de Cooperación y Desarrollo Territorial de la Universidad de Oviedo. Santa Cruz de La Palma, pp. 139-212. 
Gomera 69. Departamento de Acción Política Local de la Jefatura Provincial del Movimiento de Santa Cruz de Tenerife y Jefatura Insular de La Gomera, 1969. Santa Cruz de Tenerife, $110 \mathrm{pp}$.

GÓMEZ, A., et al. (1988): Ecoplan para la Isla de la Gomera. Fundación para la Ecología y Protección del Medio Ambiente (FEPMA), MOPU. Madrid, 322 pp.

GONZÁLEZ PÉREZ, V. (2001): «Breve historia del desarrollo rural», en Antonio Martínez. El desarrollo rural/local integrado y el papel de los poderes locales: nuevas consideraciones sectoriales y sus repercusiones en el territorio valenciano. Universidad de Alicante. Alicante, pp. 31-39.

GUERRA, R. (2004): De la autarquía a los inicios de la terciarización: la formación social canaria, 1940-1955. Inédito. La Laguna, 917 pp.

JEREZ, L. (2006): San Sebastián de La Gomera: planeamiento urbano y propiedad del suelo. Ilustre Ayuntamiento de San Sebastián de La Gomera. San Sebastián de La Gomera, 181 pp.

MARTÍN, V. (2006): «Referencias a las supervivencias semifeudales en Canarias entre 1940 y 1970 en los estudios de ciencias sociales», en XVII Coloquio de Historia Canario-Americana. Excmo. Cabildo Insular de Gran Canaria. Las Palmas de Gran Canaria.

MARTÍNEZ, A. (2001): «Las comunidades rurales y el turismo. Algunas consideraciones desde la perspectiva del desarrollo local», en martínez, A. El desarrollo rural/local integrado y el papel de los poderes locales. Nuevas consideraciones sectoriales y sus repercusiones en el territorio valenciano. Universidad de Alicante. Alicante, pp. 335-367.

MOLINERO, F. (2003): «El desarrollo de los espacios rurales. Evolución de las ideas y objetivos del Desarrollo Rural», en García Rodríguez, J.L. Desarrollo rural en territorios insulares: especial referencia a las Islas Canarias. Excmo. Cabildo Insular de La Palma, Centro de Cooperación y Desarrollo Territorial de la Universidad de Oviedo. Santa Cruz de La Palma, pp. 19-57.

PLATA, J. (1991): La comarca de Playa de Santiago en la isla de La Gomera transformaciones espaciales a lo largo del siglo XX. Excmo. Cabildo Insular de La Gomera. San Sebastián de La Gomera, $228 \mathrm{pp}$.

REYES, A. (2002): Estructura agraria, grupos de parentesco y política local en Hermigua (Gomera): un estudio antropológico (1900-1980). Excmo. Cabildo Insular de La Gomera. San Sebastián de La Gomera, 238 pp.

RODRÍGUEZ BRITO, W. (1996): Agua y agricultura en canarias. Consejería de Agricultura, Pesca y Alimentación. S/C de Tenerife, $236 \mathrm{pp}$.

RODRÍGUEZ GONZÁLEZ, R. (2001): «La aplicación de los programas europeos de desarrollo rural: dificultades y controversias», en Martínez, A. El desarrollo rural/local integrado y el papel de los poderes locales. Nuevas consideraciones sectoriales y sus repercusiones en el territorio valenciano. Universidad de Alicante, Alicante, pp. 57-68.

SANZ, F. (1999): Historia Popular de La Gomera. Edición de Autor. Santa Cruz de Tenerife, 290 pp.

SEGRELLES, J. (2001): «El aprovechamiento postproductivista del medio rural en la actualidad», en Martínez, A. El desarrollo rural/local integrado y el papel de los poderes locales. Nuevas consideraciones sectoriales y sus repercusiones en el territorio valenciano. Universidad de Alicante. Alicante, pp. 43-54.

VV.AA. (2004): El futuro de los espacios rurales. Editado por Soledad Nogués Linares, Servicio de Publicaciones de la Universidad de Cantabria. Santander, 372 pp.

VERA, J. et al. (1997): Análisis territorial del turismo. Ariel. Barcelona, 443 pp. 